\title{
Solar and Dynamo Bike
}

\author{
Yashas S, Tilak Kumar N, Yash Jinde, Vishwas Gowda B R \\ Undergraduate Student, \\ Department of Mechanical Engineering, Visvesvaraya Technical University, \\ East West Institute of Technology, Anjana Nagar, Bengaluru, Karnataka 560-091
}

\begin{abstract}
In present scenario a solar and dynamo power driven hybrid bicycle will help to solve the major problems of fuel prices, especially the petrol is rising steadily day by day. Again, the pollution due to vehicles in metro cities and urban areas is increasing continuously. To overcome these problems, an effort is being made to research some other alternative sources of energy to drive the Bicycle. Also for a middle class people it is difficult to purchase fossil fuel vehicles as they are expensive. By considering all these factors, a search for some way to cater these economically poor people as well as to provide a solution for the environmental pollution was in progress.

The solar and dynamo assisted hybrid bicycle is driven by direct current motor fitted in the front axle housing and run on electrical energy. The solar panels mounted on the carriage will charge the battery and which in turn drive the hub motor.

When the bicycle is idle or stationary in parking, the solar panel will charge the battery and a pair of 48-volt dynamo is fixed on the rear wheel of the bicycle will charge the battery when the bicycle is running on the road. This arrangement will replace the petrol engine, the gear box and the fuel tank in case of a two-wheeler or a gear shifting arrangement of a bicycle.
\end{abstract}

Key words: Travelling, Dynamo Motor, Electric Energy, Solar Panels.

\section{INTRODUCTION}

Solar and dynamo bike is designed to meet the present challenges of conventional bikes and also to reduce the pollution caused by conventional bikes. The fast depletion of fossil fuels due to the exponential increase in demand and global warming due to the emission of $\mathrm{CO} 2$ made engineers and scientists to look for an alternative source of energy which is renewable, eco-friendly, affordable and available.

Among the renewable sources like wind, tidal, geothermal and solar energy, solar power is promising in nations like India which is in the tropical region. India spends a large amount of foreign exchange to import crude oil.

By using solar energy to drive the vehicles, the dependency on the import of crude oil can be reduced and reasonable amount of foreign exchange can be saved.

A solar bike is a bike which runs using the electrical energy of batteries to run the hub motor which ultimately runs the bicycle. Solar energy is used to charge the battery. Two Photovoltaic cells may be used to harness solar energy to generate voltage to charge.

Solar bike are not sold generally in our everyday life but there manufacturing can be increased to prevent environmental pollution. Primarily these are used as an practical projects and are also sometimes sponsored by government agencies. Solar bike use photovoltaic cells that convert solar energy into required voltage to charge the battery.

There are two types of solar panels that are generally used that is polycrystalline panels and microcrystalline solar panels. The polycrystalline panels have less efficiency as compared to microcrystalline panels. Polycrystalline panels have efficiency of approximately $15-20 \%$, microcrystalline panels have efficiency of $50-60 \%$. There are different types of batteries used in electric vehicles like lead acid batteries, lithium ion batteries, Nickel cadmium batteries, etc. Different batteries they have their different advantages for different applications.

As far as solar bike are concerned lead acid and lithium ion batteries are most commonly used. Lead acid batteries have lower cost, higher current carrying capacity but have smaller life and are heavier. Slowly solar bike have gathered attention from all over the world.

\section{LITRATURE SURVEY}

To perform this project, literature review has been made from various sources like journals, Book, article and other After going to the number of above literature survey as to be drawn out the main objective of this survey is to drive the bike using renewable energy sources such as solar, dynamo and wall charger use to charge the battery using electrical energy.

The main aim of this survey is to run the bicycle using dynamo power. A pair of dynamo will be fixed on the rear wheel without using peddling dynamo charge the battery and produced electricity and stored in battery and battery supply power to the hub motor of the front axle and bicycle run on the road.

\subsection{GOODMAN.J.D : $\{2010\}$}

With the expanding utilization of regular assets of petroleum, diesel it is important to move our way towards exchange assets like the electric bicycle and others since it is important to distinguish better approach for transport. Electric bicycle is an alteration of the current cycle by utilizing electric vitality and furthermore sunlight based vitality if sun powered boards are given, that would aggregate up to increment in vitality generation. Since it is vitality proficient, electric bicycle is less expensive and reasonable to anybody. It can be utilized for shorter separations by individuals of all ages. It can be devised consistently. The most crucial component of the electric bicycle is that it doesn't devour non renewable energy sources in this manner sparing crores of outside monetary standards. The second most critical element is it is sans contamination, eco well disposed and quiet in operation. For counterbalancing ecological contamination utilizing of 
on board Electric Bicycle is the most feasible arrangement. It can be accused of the assistance of AC connector if there is a crisis. The Operating expense per/ $\mathrm{km}$ is less and with the assistance of sun powered board it can reduce up more. Since it has less segments it can be effectively destroyed to little segments, along these lines requiring less support.

\subsection{HAMEED MAJEEDSABER : \{ 2014\}}

The current study had been conducted in Sam Higginbottom Institute of Agriculture, Technology \& Sciences, and Allahabad, India to assess the potential of installing solar panels on the roof tops of its various buildings. A survey within SHIATS was conducted to obtain latitude and longitude points for each of the building considered in the current analysis. Google Earth's high resolution imagery has been utilized for digitizing the roof tops of the buildings. Spatially distributed solar radiation maps are generated for the study area and the data was extracted for each of the building. The potential of installing solar panels on SHIATS's buildings was assessed by analysing the total solar radiation that potentially gets accumulated on each building. The buildings are ranked according to amount of solar radiation they accumulated.

\subsection{FOGELBERG.F :\{ 2014\}}

From the future energy system perspective, it is important to identify new ways of transport and generation of electricity and solar powered E-bike pools may just be such a case. E-bikes are an order of a magnitude more energy efficient than car, bus or other heavy transport mode. Using a solar panel at 0.2-0.8 $\mathrm{m} 2$ per E-bike has been shown to be enough to supply the early energy demand by the E-bike pool depending on simulated system usage (3-10.8 trips/(bike \& day)). The computed area is smaller than the assumed maximum area at 3-3.8 m2/Ebike meaning that energy self-sufficiency on a yearly scale can be accomplished without running out of space. Using larger panel area than $0.2-0.8 \mathrm{~m} 2$ per E-bike will for a gridconnected system lead to net electric energy production. A modal shift from bus or car to solar powered E-bike pool would thus not only reduce emissions and energy use but can potentially also lead to net production of electricity from solar energy. The recommended system design is to have a grid-connected system as an off-grid solution would not utilize the solar irradiation fully. Coupling the gridconnected system with a buffer battery was shown to increase the share of time the system is independent of energy from the grid from about $40 \%$ to $80 \%$ at $2 \mathrm{~m} 2$ solar panels per E-bike.

\subsection{AIKENHEAD.G.S : $\{2011\}$}

On-board solar power generation using the Elora Research Station solar irradiance data supplied only $13 \%$ of the required power for typical city riding conditions excluding the effects of wind and uneven riding terrain. Riding conditions that provided greater than $25 \%$ of the required power through on-board solar power generation were primarily limited to ground speeds $(\mathrm{Vg})$ much slower than typical city riding speeds. The use of on-board solar power generation is a viable option for recharging the system battery. One full day of solar charging replenishes $138.20 \mathrm{Wh}$ (approximately $42 \%$ of battery capacity), which is sufficient to supply $100 \%$ of PTotal for trip distances up to $30 \mathrm{~km}$. The use of a two-wheeled bicycle trailer adds significant solar power generation capabilities; however, the increase in overall system size limits the practicality of a compact bicycle system for city use. Future considerations for the research include incorporating solar irradiance data that accounts for different solar panel orientations (i.e., $\beta$ greater than 0 ) and applying this analysis in other geographical locations of known solar irradiance. While on-board solar power generation appears to be a viable alternative for offsetting environmental pollution of rising PAEB use, this technology requires further development to optimize the direct use of solar power during riding. However, using on-board solar power generation for recharging system batteries while not in transit is feasible for reducing dependency on the conventional power grid.

\subsection{PALAK DEASI : $\{2016\}$}

From this project, we conclude that this vehicle is quite suitable for almost all the humans. For the propulsion of the wheeled vehicle with which may be provided the straightforward movement of tricycle over an existing vehicle with the assistance of various mechanism and combination of technology which can have larger advantage to the physically disabled persons to propel the vehicle. From the above conclusion it is decided that use of lever power tricycle is suitable for handicap person and also for normal person and mechanical work is most comfortable for use.

\section{OBJECTIVES AND METHODOLOGY}

An attempt is made in the fabrication of a Solar and Dynamo Bike for a two-wheeler. There are many vehicles that came to influence in the existing world. Their operating systems are based on fossil fuel system. At the present scenario the fossil fuel can exceed only for a certain period after that we have to go for a change to an other methods. Solar energy is captured from the sun using solar panels mounted on the rear end of the bicycle. These panels are connected to a boost converter so as to boost the voltage to the required level. The arrangement is further connected to a battery.

The battery is charged using this solar output as the entire power transfer is Direct current in this case. This battery is connected to a DC motor. The battery can also be charged using a wall charger in case of absence of sun. A brush-less DC motor is preferred, because of no maintenance, high efficiency, and low noise and also because of the absence of brushes we don't find sparking in a BLDC motor. A synchronized motor controller is used here for the working of the motor. Also a throttle is used here to increase the speed of the Solar and Dynamo Bike. This accelerator is directly connected to the motor controller which in turn controls the speed of the motor. The bicycle can also be run using mechanical pedaling in the absence of sun or when the battery is drained out. 
Thus, we have tried to design and fabricate solar and dynamo bike, which would produce the cheaper \& effective result than the existing system.

\section{WORKING PRINCIPLE}

\section{BLOCK DIAGRAM}

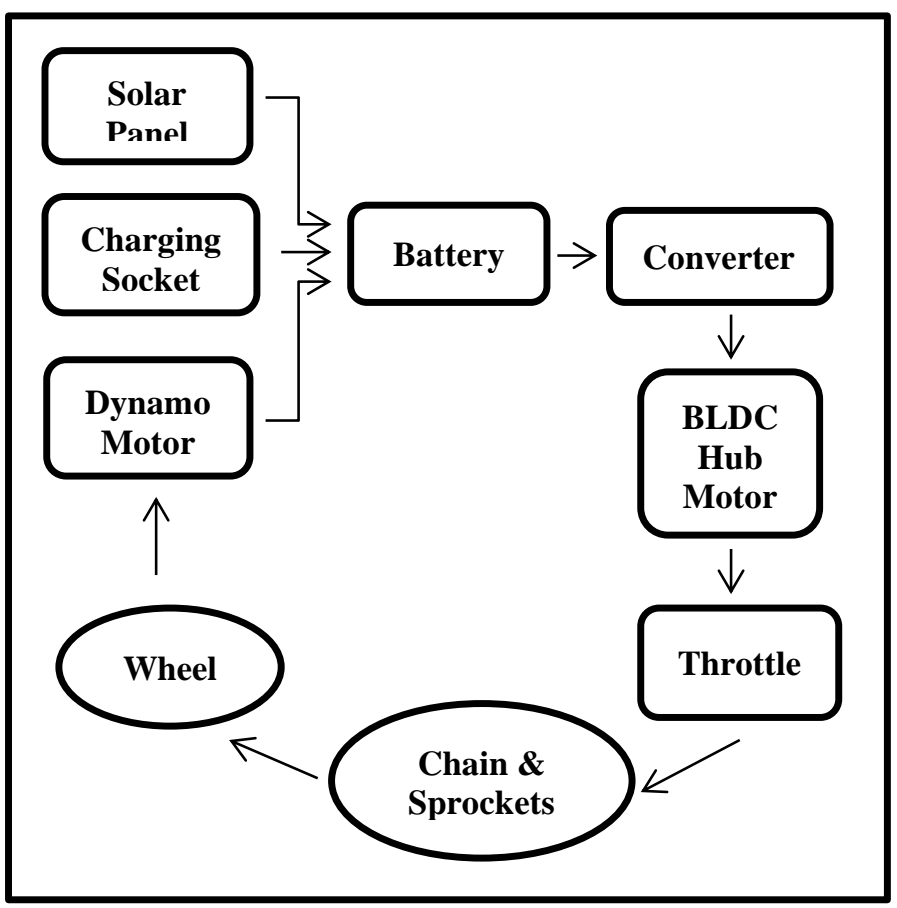

Figure 1 Block diagram of Solar and Dynamo Bike

\section{What is Solar and Dynamo Bike?}

The Solar and Dynamo Bike is a bike which is driven with the help of battery where the electric power in the battery is generated from dynamo and solar panels.

Working principle: It works on the principle that the electromotive force of an A.C. motor which receives electrical energy stored in D.C. battery is converted with the help of D.C. to A.C. converter.

Operation: Initially, electric power is generated from dynamo motor due to rotational motion of a wheel and also from a solar panels where it will be installed on the bike. So this electrical energy or power is stored in a battery where the direct current is converted into alternative current. Therefore this alternative current helps to rotate the sprocket wheel with the application of acceleration. Thus a Solar and Dynamo Bike can be driven.

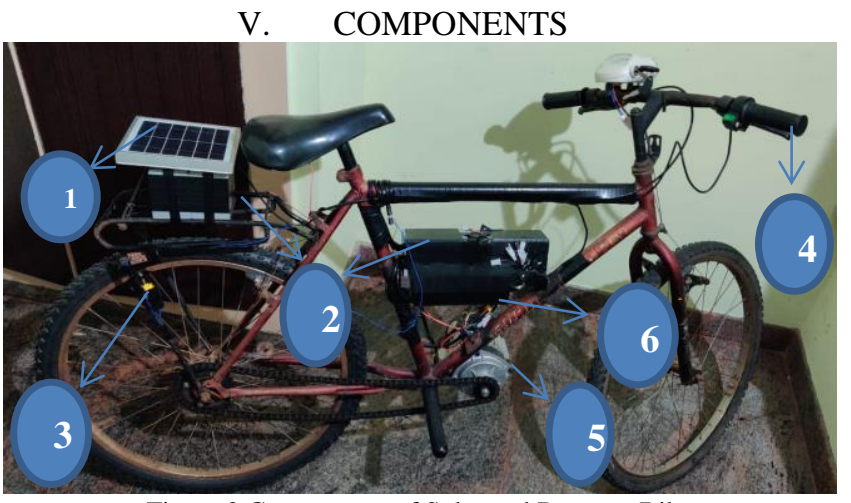

Figure 2 Components of Solar and Dynamo Bike
[1].Solar Panel
[2].Battery
[3].Dynamo Motor
[4].Throttle
[5].BLDC Hub Motor
[6].Converter

\subsection{Dynamo motor:}

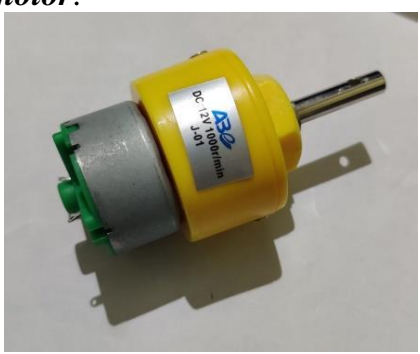

Figure 3 Dynamo motor

Its specifications are as follows:

- 1000 RPM

- Voltage Rating: 12 Volts

- Cooling: Air -cooled

- Bearing: Single row ball

\subsection{Battery:}

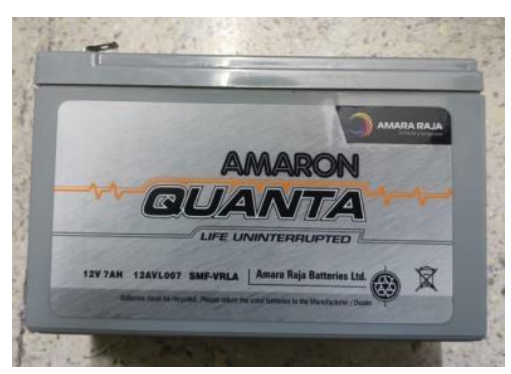

Figure 4 Battery

- 48V Battery is required.

- So we have used 4 Batteries of $12 \mathrm{~V}$.

- Ampere 7 AH. 


\subsection{Chain Drive:}

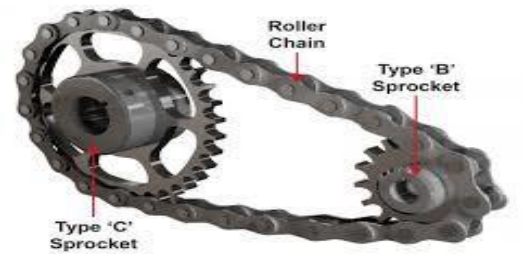

Figure 5 Chain drive

The Chain is an array of links held together with each other with the help of steel pins. This type of arrangement makes the chain more enduring, long lasting and better way of transmitting rotary motion from one gear to another. The advantage of chain drive over traditional gear is that, the chain drive can transmit rotary motion with the help of two gears and a chain over a distance whereas in traditional many gears must be arranged in a mesh in order to transmit motion.

\subsection{Frame:}

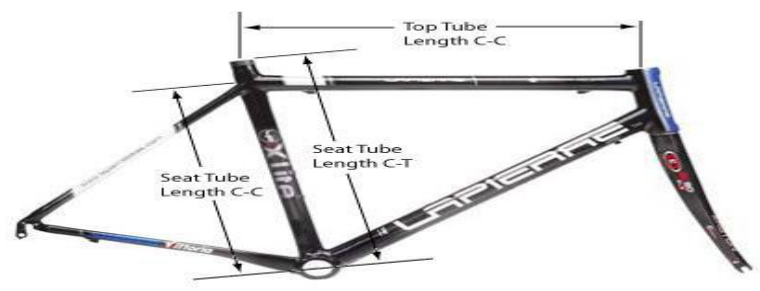

Figure 6 Frame

The Frame is made up of M.S. along with some additional light weight components. The frame is designed in such a way that it can sustain the weight of the person driving the unit, the weight of load to be conveyed and also to hold the accessories like motor. Also it should be designed to bear and overcome stresses which may arise able to due to different driving and braking torques and impact loading across the obstacles. It is drilled and tapped enough to hold the support plates.

\subsection{Sprockets:}

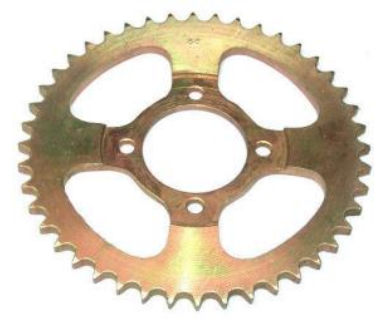

Figure 7 Sprockets

The chain engaging with the sprocket converts rotational power in to rotary power and vice versa. Sprockets which look like a gear may differ in three aspects

- Sprockets have many engaging teeth but gears have only one or two.

- Teeth of the gear touch and slip against each other but there is basically no slippage in case of sprocket

- The teeth shapes are different in gears and sprockets.

\subsection{Solar Panels:}

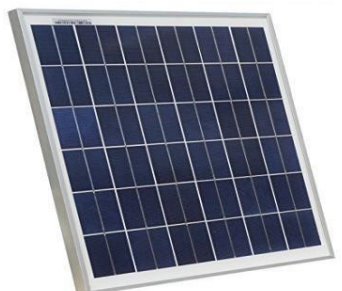

Figure 8 Solar panels

We use solar panels of $16 \mathrm{~W}$ having dimension $18 * 18 \mathrm{~cm}$ and capacity $12 \mathrm{~V}$.

\subsection{BLDC Hub motor:}

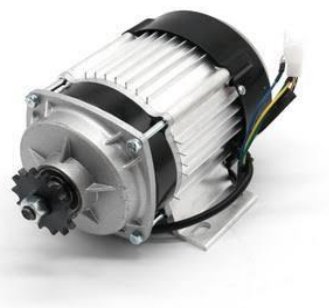

Figure 9 BLDC hub motor

BLDC Hub motor electromagnetic fields are supplied to the stationary windings of the motor. The outer part of the motor turning the attached wheel . Energy is transferred in a brushless motor electronically, eliminating physical contact between stationary and moving parts BLDC Motor powered by DC electricity via an inverter or switching power supply which produces an alternative current to drive each phase of the motor via a closed loop controller. The controller provides pulses of current to motor windings that control the speed and torque of the Motor. In BLDC motor the roles of the coils are opposite compared to normal DC motor: the inner part having the coils is stationary and the magnet rotates around this coil. The electronic circuit induces power in the inner copper coils in turn, making the outer body spin around the copper coils. There are many small magnetic field sensors attached between some of the coils. These sensors are known as Hall-effect sensors. When the outer permanent magnet passes through the sensors, the sensors sense the position of the north and south poles of the rotor and then activate the required coils for continuous rotation. Capacity of BLDC Motor is 750 watt and 48 volts.

\subsection{Full twist throttle:}

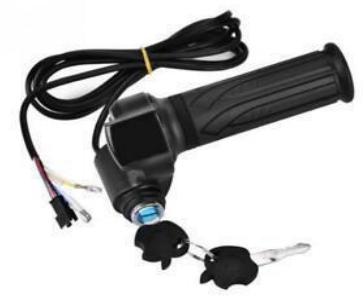

Figure 10 Full twist throttle 
The full twist throttles antithesis of thumb throttles as they are the largest type of bike throttle and require the whole hand to operate. The full twist throttle takes up the entire end of the handlebar, to operate it, the rider simply grabs a handful of throttle and twist it back towards himself. We preferred full twist throttle because they are operated by the full hand all five-finger grip that rider. And use your wrist to accelerate.

\subsection{Converter:}

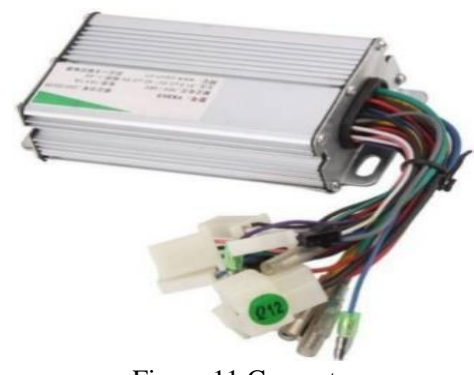

Figure 11 Converter

The converter converts Direct current (DC) to Alternative current (AC).

\section{ADVANTAGES}

- Renewable energy source.

- Reduces the use of fossil fuels.

- Technological development

- Reduces air and noise pollution

- Low maintenance cost

- This can be used even in the absence of sun light

- It has an alternate source of power generation using dynamo

- It is a combination of both non-polluting and cost efficient.

\section{FABRICATED MODEL}

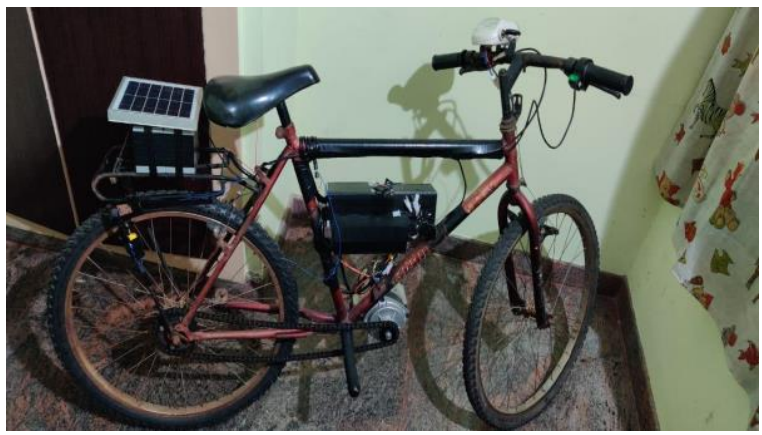

Figure 12 Side View
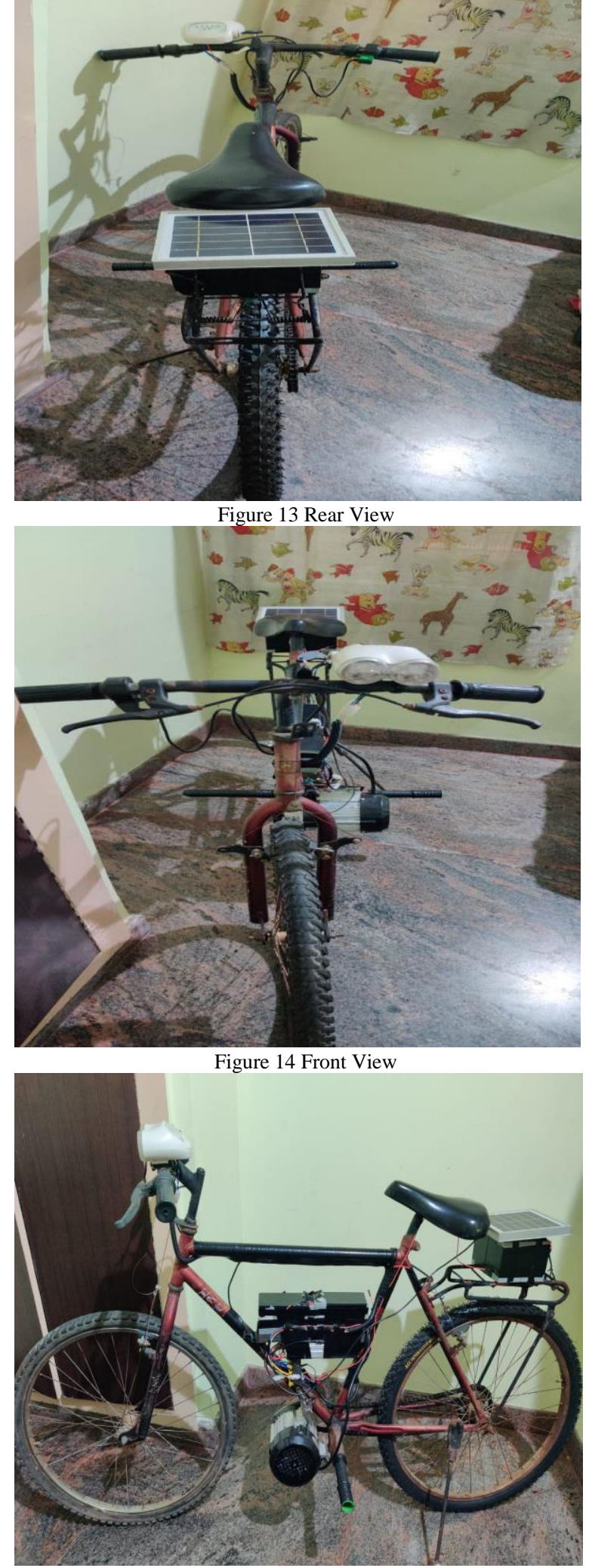

Figure 15 Side View

\section{CONCLUSION}

With the increasing consumption of natural resources of petrol, diesel it is necessary to shift our way towards alternate resources like the Electric bike, Solar and Dynamo bike and others because it is necessary to identify new way of transport. Solar and Dynamo bike is a modification of the existing cycle by using dynamo and 
also solar energy if solar panels are provided, that would sum up to increase in energy production. Since it is energy efficient, this bike is cheaper and affordable to anyone. It can be used for shorter distances by people of any age. It can be contrived throughout the year. The most vital feature of this bike is that it does not consume fossil fuels thereby saving crores of foreign currencies. The second most important feature is it is pollution free, eco - friendly and noiseless in operation. For offsetting environmental pollution using of on - board Solar and Dynamo Bike is the most viable solution. It can be charged with the help of AC adapter if there is an emergency. An Operating cost per $/ \mathrm{km}$ is very less and with the help of a solar panel it can be lessen up more. Since it has fewer components it can be easily dismantled to small components, thus requiring less maintenance.

\section{FUTURE SCOPE}

Our project "Solar and Dynamo Bike" is mainly intended to fabricate a Bike with renewable energy source solar and kinetic rotational energy. The bike can further be improved by using solar panels on the front and the rear frames of the mudguards or other places which would be responsible for trapping solar energy \& converting the same into electric energy thereby improving the battery's efficiency. The solar and dynamo bike will replace the fossil fuel vehicles in future.

\section{REFERENCES}

[1] "Energy storage system in electrical system" Available: http://ieeexplore.iee. org

[2] William C. Morchin "Battery-Powered Electric Bicycles Available: http://ieeexplore.ieee.org

[3] GOODMAN, J. D. (2010, Jan 31). An Electric Boost for Bicyclists. The New York Times.

[4] Hameed Majeed Saber and Deepak Lal, Assessment of Solar Energy Distribution For Installing Solar Panels Using Remote Sensing \& GIS Techniques, International Journal of Advanced Research in Engineering and Technology (IJARET) Volume 5, Issue 10, October (2014), pp. 157-164.

[5] FOGELBERG, F. (2014). Solar Powered Bike Sharing System. Goteberg, Sweden: Viktoria Swedish ICT.

[6] Aikenhead , G. S. (2011). Bicycle Applications for On-Board Solar Power Generation. 9,10.

[7] Prof. Palak Desai, P. D. (June 2016). Design and Fabrication of Solar Tri Cycle. International Journal of Engineering Sciences \& Research, 664.

[8] Barve, D. S. (2016). Design and Development of Solar Hybrid Bicycle. International Journal of Current Engineering and Technology, 377,378,379,380.

[9] Barve, D. S. (March 2016). Design and Development of Solar Hybrid Bicycle. International Journal of Current Engineering and Technology, 380

[10] "Dynamic Modeling and Simulation of Electric Bicycle Ride Comfort" Is available: http://ieeexplore.ieee.org 